\title{
French categorization norms for 70 semantic categories and comparison with Van Overschelde et al.'s (2004) English norms
}

\author{
Steve Bueno and Hakima Megherbi \\ Université de Paris 13, UTRPP-EA 3413, Villetaneuse, France
}

\begin{abstract}
The present methodological note provides categorization norms for 70 semantic categories collected from 200 participants. The categories were mainly derived from a French translation of the Van Overschelde, Rawson, and Dunlosky (2004) inductor terms including a large set of semantic categories. Our study also extends recent French norms (Léger, Boumlak, \& Tijus, 2008; Marchal \& Nicolas, 2003) and tests their stability. These 70 categories constitute the widest French categorization norms to date and will be of use to studies in the fields of both linguistics and psycholinguistics. A cross-linguistic comparison, with both quantitative and qualitative results, is also performed, which should prove useful for bilingual and/or cross-linguistic studies. The norms collected for all 70 categories are available for download as supplemental materials from http://brm.psychonomic-journals .org/content/supplemental.
\end{abstract}

Categorization is the cognitive process without which the world would appear chaotic. From birth, humans store a phenomenal amount of knowledge derived from their interactions with objects and surrounding circumstances. Daily, they manipulate objects, see other people using these objects, and store them in memory. These internal representations are brought together under the term of semantic knowledge. As outlined by Cree and McRae (2003), the memory network involved in the retrieval, processing, and, possibly, the output of this semantic knowledge is called semantic memory. Continuously growing from early childhood, this network is fully efficient when adult and remains quite efficient in normal aging (Luo \& Craik, 2008). Obviously, an exhaustive description of the content of this memory is utopian. Nevertheless, it is possible to examine its structure and mechanisms via behavioral studies (Bueno \& Frenck-Mestre, 2008; McRae \& Boisvert, 1998; Neely, 1991; Quinn \& Kinoshita, 2008), neuroimaging studies (Dehaene et al., 1998), or computerized simulations involving a cross-section of these representations in memory (Masson, 1995; Plaut, 1995; Plaut \& Booth, 2000). Generally, the building of the experimental material of these studies depends on carefully checked norms of association, categorization, or semantic features (see, e.g., for these three types of norms, Ferrand \& Alario, 1998; Van Overschelde, Rawson, \& Dunlosky, 2004; McRae, Cree, Seidenberg, \& McNorgan, 2005, respectively). The majority of studies on semantic memory have been performed in English and certainly depend on norms produced in this language.

The present article provides French categorization norms for 70 semantic categories in adults in the aim of extending the currently available norms to the French language. We have adopted the methodology of Van Overschelde et al.'s (2004) English norms and will present comparisons between the two studies in order to investigate their cross-linguistic generalization and to be of use for future cross-linguistic research.

The first categorization norms were in English (Battig \& Montague, 1969; Cohen, Bousfield, \& Whitmarsh, 1957) and, as reported by Van Overschelde et al. (2004), were used in more than 1,600 published articles in approximately 220 different periodicals. Recently, Van Overschelde et al. updated and increased Battig and Montague's norms by testing 70 semantic categories from over 700 North American participants (see Table 1 for number of participants and categories for English norms). Given the speed of language change, categorization norms (and to a lesser extent, associative norms) rapidly become obsolete, necessitating relatively frequent updating.

To collect their normative data, Van Overschelde et al. (2004) asked participants from three different universities to perform a production task for 70 semantic categories. Among these categories, 56 were derived from Battig and Montague (1969), and 14 were added on the basis of three different criteria (general, ad hoc, and domain-relevant categories). Categories were displayed one by one, and the participants had $30 \mathrm{sec}$ to typewrite a maximum number of exemplars per category. The entire experiment was computerized and allowed quantitative and qualitative measures.

Norms can reflect the use of the language for a given, relatively short period and can be considered to be a sociocultural "snapshot." Thus, Van Overschelde et al. (2004) 
Table 1

Number of Categories and Participants Tested in a Set of English and French Semantic Categorization Norms

\begin{tabular}{|c|c|c|}
\hline Reference & $\begin{array}{l}\text { Number of } \\
\text { Categories }\end{array}$ & $\begin{array}{c}\text { Maximum } \\
\text { Number of } \\
\text { Participants } \\
\text { per Category }\end{array}$ \\
\hline \multicolumn{3}{|l|}{ English Norms } \\
\hline Cohen, Bousfield, \& Whitmarsh (1957) & 43 & 400 \\
\hline Battig \& Montague (1969) & 56 & 442 \\
\hline Van Overschelde, Rawson, \& Dunlosky (2004) & 70 & 710 \\
\hline \multicolumn{3}{|l|}{ French Norms } \\
\hline Charles \& Tardieu (1977)* & 28 & n.a. \\
\hline Denis $(1978)^{*}$ & 16 & 60 \\
\hline Tourrette (1979)* & 30 & 114 \\
\hline Cordier (1980) & 5 & 280 \\
\hline Dubois (1983) & 22 & 75 \\
\hline Marchal \& Nicolas (2003) & 38 & $85^{\mathrm{a}}$ \\
\hline Léger, Boumlak, \& Tijus (2008) & 21 & 100 \\
\hline The present study & 70 & 200 \\
\hline
\end{tabular}

*Unpublished norms. aTwo distinct groups of 85 young and 85 elderly French speakers.

computed a measure of a generational stability on Battig and Montague's (1969) data through Pearson productmoment correlations. Fifty-four of the 56 categories showed a good generational stability. As was reported by Van Overschelde et al., elements that constitute good category exemplars can change depending on societal evolution. For instance, the authors report the exemplars of diseases that either declined (tuberculosis) or appeared (AIDS) during the 35-year-old period between their study and that of Battig and Montague. As such, changes mainly concern categories dealing with "trends" (e.g., A TYPE OF DANCE or A FEMALE FIRST NAME), whereas categories such as A COLOR Or A PART OF THE HUMAN BODY show a strong stability.

The question of possible differences within the same cultural group has been dealt with in various American norms. Norms are frequently collected, within the same time frame, from different geographical locations (Maryland and Illinois for Battig \& Montague, 1969; Colorado, Maryland, and North Carolina for Van Overschelde et al., 2004) and include a relatively high number of participants (however, never surpassing 200 per location). Van Overschelde et al. computed Pearson product-moment correlations and showed a high degree of geographical stability within the United States, as did Battig and Montague with their own data. Such results from single regions make it possible for us to consider that collecting data can be extended to the entire country.

In comparison with English categorization norms, published French norms for a large set of categories are markedly rarer. Until recently (Léger, Boumlak, \& Tijus, 2008; Marchal \& Nicolas, 2003), only norms dealing with a small set of categories (Cordier, 1980; Dubois, 1983), publications of limited circulation, and/or unpublished works were the reference for French semantic categorization norms (Charles \& Tardieu, 1977; Denis, 1978; Tourrette, 1979). Table 1 sums up the number of categories and participants tested in several of these semantic categori- zation norms. In general, to overcome the lack of norms in French, researchers make ad hoc pretests on a small number of participants (generally, fewer than 40), with no aim of publishing their normative data.

Marchal and Nicolas (2003) collected data on 38 semantic categories from 85 young and 85 elderly adults. The participants' task was to write the first four exemplars that came to mind with no time constraint. In Léger et al.'s (2008) study, three groups of 100 young adults participated, each of which was involved in collecting data for 7 semantic categories, so that a total of 21 categories was processed. Their task was to write the maximum number of exemplars per category, with no time constraint. Whereas Marchal and Nicolas gave no criterion concerning the distinction of the different categories, Léger et al. arranged their 21 categories into 3 superordinate categories: natural objects $(N=9)$, artifactual objects $(N=9)$, and human activities $(N=3)$. These two French studies shared 13 categories.

The aim of the present study was to obtain categorization norms for a set of 70 semantic categories, collected in 200 young French adults. In comparison with recently published French norms (Léger et al., 2008; Marchal \& Nicolas, 2003), the present study substantially increases the number and the diversity of categories and constitutes the widest base of French categorization norms to date. Such diversity was certainly lacking for studies that needed to deal with different approaches to the study of semantic memory structure. Our study provides 55 and 56 categories in addition to those in Marchal and Nicolas's and Léger et al.'s studies, respectively, while sharing 15 and 14, respectively, with those studies (see Tables 4 and 5). A measure of stability will be given for these common categories in the Results section.

Given the rise in the number of cross-linguistic and/or bilingual paradigms, the necessity of adopting a common methodology goes without question. We adopted that in Van Overschelde et al.'s (2004) study, which thus enabled 
the comparison of French and English semantic memory processes. Moreover, collection of the data in that study and in the present one was obtained in a relatively short time period, which certainly permits good generational stability. To fill the void in French norms with respect to number of categories, we translated 59 of the inductor terms in Van Overschelde et al. Eleven categories were discarded due to a high American specificity (example: A STATE). We replaced them by 11 new categories (see the Materials section for a description and Table 3).

Ordering each semantic category in superordinate categories, such as living, nonliving, natural, artifacts, broad, or narrow, appears quite difficult. The overlap between categories' dimensions makes a general classification difficult (e.g., UN OISEAU/A BIRD is both a living and a natural thing, whereas UN PHÉNOMENNE MÉTÉOROLOGIQUE/A WEATHER PHENOMENON is both a nonliving and a natural thing). Whereas the dichotomy between a finite and a nonfinite category is manifest (e.g., A MONTH vs. A GIRL'S FIRST NAME), the dichotomy between large and narrow categories is again difficult to draw. In this connection, Quinn and Kinoshita (2008) noted that "what has been called a large category in one study may be referred to as a small/narrow category in another" (p. 288). Such distinctions are therefore relative ones (e.g., UNE COULEUR/A COLOR can be classified as a natural thing regarding the green color of the chlorophyll making up a plant but can be classified as an artifact if it refers, for instance, to a chemical ink). Given the complexity involved in classifying semantic categories, it was not relevant to provide a classification in the present study.

To sum up, our study provides a large view of the categorization process, since it deals with a large diversity of semantic categories and provides materials for different approaches in the study of semantic memory structure.

\section{METHOD}

\section{Participants}

Two hundred eighteen students participated in the collection of the norms, which lasted roughly $45 \mathrm{~min}$. The participants were recruited from two universities (Paris 13-Villetaneuse and Paris 8-SaintDenis). To broaden our sample, participants were recruited from three different majors (psychology, linguistics, and economics; $N=$ 100,50 , and 50, respectively). Eighteen participants were ruled out because they either were not native French speakers or surpassed the age limit determined for the group. The results were computed on a maximum of 200 students per category $(M=196, S D=10.93$, range $=147-200)$. The group consisted of 162 women and 38 men (mean age $=22.3$ years, $S D=5.88$ ).

\section{Materials}

The materials consisted of the 70 semantics categories (see Table 3). Fifty-nine of them were taken from Van Overschelde et al. (2004). Actually, 11 categories were discarded from the latter since they were too culturally marked and/or elicited proper nouns as answers (e.g., A FOOTBALL TEAM NAME, A COLLEGE OR UNIVERSITY, A STATE) and were replaced by 11 new categories; 4 categories were selected to take into account "contemporary" matters (e.g., UN PÉRIPHÉRIQUE INFORMATIQUE/A PERIPHERAL DEVICE), 4 permitted further comparisons between children and adults (e.g.,
UN TYPE D'HABITATION ANIMALE/A TYPE OF ANIMAL DWELLING), and 3 referred to never studied categories of objects (e.g., UN OBJET DE DECORATION/AN INTERIOR DECORATION). TO our knowledge, none have been tested in previous norms (in either English or French), which thereby increases the diversity of available categories. Consequently, the overlap of the present and previous norms allows for cross-linguistic comparisons for 59 semantic categories. Although language-specific comparisons were not our priority, we will report herein comparisons with the French norms collected by Marchal and Nicolas (2003) and by Léger et al. (2008) for 15 and 14 common categories

\section{Procedure}

The present study was not computerized, contrary to Van Overschelde et al.'s (2004) study. ${ }^{1}$ This constitutes the main difference in procedure with the present study. Group sessions were held between March and May 2008. The participants were given a 70-page, A5format booklet including the name of a semantic category on each odd page. The instructions were presented on the booklet cover (and were adapted for the noncomputerized situation; see the Appendix); they specified that the task was to handwrite the maximum number of exemplars for each semantic category in a 30-sec time window. A category instance was given (UN MATERIEL DE BUREAU/A STATIONERY), as were possible responses to this category (e.g., trombone/ paper clip, stylo/pen, agrafeuse/stapler). The experimenter produced a "beep" every $30 \mathrm{sec}$, indicating that the participants had to move to the next category. A 2-sec latency period was taken into account for the participants to turn the page. In addition, if the participants did not understand the name of the category, it was specified to quietly wait until the end of the 30 -sec time window and to resume when the following category began. Two breaks were proposed: one at the first third of the booklet, the other at the second third. Ten different randomization orders were created to avoid list effects as well as communication among participants during the data collection. Care was taken to avoid the proximity of certain categories, mainly to prevent priming effects (e.g., $U N$ TYPE DE DANSE/A TYPE OF DANCE was never adjacent to UN STYLE DE MUSIQUE/A STYLE OF MUSIC, or UN MEUBLE/AN ARTICLE OF FURNITURE was never adjacent to UNE CHOSE FAITE DE BOIS/A THING MADE OF WOOD). Three dependent variables concerning produced exemplars were collected inside each category: name of exemplars (both in French and English), total, and first occurrence (see Table 2 for the example of UNE PIERRE PRECIEUSE/A PRECIOUS STONE). The data for the whole category set are available for total of different entries per category, potency, and rank. These six variables will be described in the Results section below.

Posttest. Following collection of the category exemplars, a posttest was performed to make sure that the name we gave to each category (or its translation) was fully understandable. In this perspective, 66 new participants were asked to determine the name of the category from the provided exemplars. Each participant received a 70page, A5-format booklet. All the exemplars of a specific semantic category found in our main study were written on each page of this booklet. The participants had to write down the name of the semantic category that could include all the exemplars given. The participants were given the exemplars in alphabetic order. Responses such as $U N E$ DANSE, UN TYPE DE DANSE, Or UNE SORTE DE DANSE (A DANCE, A TYPE OF DANCE, or A KIND OF DANCE) were considered as a unique correct response. The results of this "opposite exercise" indicated that the correct name of the semantic category derived from exemplars was easily recovered by the participants. The results of this posttest could be seen as a sort of reliability estimate. However, the participants had difficulties with three specific semantic categories (UN MANDAT POLITIQUE/AN ELECTIVE OFFICE, UN CONDIMENT/A SUBSTANCE FOR FLAVORING FOOD, and UN OBJET CÉLESTE/A CELESTIAL OBJECT). Nearly $25 \%$ of the participants did not give a response to these categories. These difficulties must then be taken into account when these categories are used in semantic tasks. 
Table 2

Entire Set of Responses for the Category UNE PIERRE PRÉCIEUSE/A PRECIOUS STONE

\begin{tabular}{|c|c|c|c|c|c|}
\hline \multicolumn{3}{|c|}{ The Present Study } & \multicolumn{3}{|c|}{$\begin{array}{l}\text { Van Overschelde, Rawson, } \\
\text { and Dunlosky (2004) Study }\end{array}$} \\
\hline French Name & Total (199) & $\begin{array}{c}\text { First } \\
\text { Occurrence }\end{array}$ & English Name & Total (647) & $\begin{array}{c}\text { First } \\
\text { Occurrence }\end{array}$ \\
\hline diamant & .89 & .36 & diamond & .92 & .50 \\
\hline rubis & .75 & .32 & ruby & .78 & .15 \\
\hline emeraude & .62 & .06 & emerald & .51 & .06 \\
\hline saphir & .53 & .09 & sapphire & .49 & .02 \\
\hline améthyste & .15 & .03 & amethyst & .18 & .02 \\
\hline or & .15 & .05 & gold & .14 & .02 \\
\hline topaze & .14 & .02 & topaz & .12 & .01 \\
\hline jade & .08 & .02 & jade & .06 & \\
\hline aigue marine & .06 & .01 & aquamarine & .04 & .00 \\
\hline argent & .05 & & silver & .08 & \\
\hline cristal & .05 & .01 & crystal & .04 & .00 \\
\hline ambre & .04 & & amber & .02 & .00 \\
\hline lapis-lazulis & .04 & & lapis & .00 & \\
\hline opale & .04 & .01 & opal & .18 & .01 \\
\hline agate/agathe & .03 & .02 & agate & .00 & .00 \\
\hline perle & .03 & & pearl & .22 & .01 \\
\hline quartz & .03 & & quartz & .06 & \\
\hline bijou & .02 & .01 & jewel & .03 & .00 \\
\hline onyx & .02 & & onyx & .04 & .00 \\
\hline zirconium & .02 & & zirconium & .01 & \\
\hline carat & .02 & & carat & .00 & \\
\hline aventurine & .01 & & aventurine & - & - \\
\hline bague & .01 & .01 & rings & .00 & \\
\hline grenat & .01 & & garnet & .11 & .01 \\
\hline jaspe & .01 & & jasper & .00 & \\
\hline joyau & .01 & & jewelry & .00 & \\
\hline nacre & .01 & & mother-of-pearl & .00 & \\
\hline opaline & .01 & & opaline & - & - \\
\hline pierre & .01 & & stone & - & - \\
\hline pierre de lune & .01 & .01 & moonstone & .00 & \\
\hline turquoise & .01 & & turquoise & .05 & .01 \\
\hline citrine & .01 & & citrine & .00 & \\
\hline collier & .01 & & necklace & - & - \\
\hline corail & .01 & & coral & .00 & .00 \\
\hline diadème & .01 & & tiara/diadem & - & - \\
\hline gemme & .01 & .01 & gem(stone) & .19 & .11 \\
\hline granite & .01 & & granite & .01 & .00 \\
\hline ivoire & .01 & & ivory & .00 & \\
\hline météore & .01 & & meteor & - & - \\
\hline musée & .01 & & museum & - & - \\
\hline œil de tigre & .01 & & tiger's eye & .01 & \\
\hline olivine & .01 & & olivine & - & - \\
\hline pierre noire & .01 & & black chalk & - & - \\
\hline tanzanite & .01 & & tanzanite & .02 & \\
\hline
\end{tabular}

\section{RESULTS}

Data for the 70 categories from the 200 booklets were manually entered into an Excel spreadsheet. Fewer than $1 \%$ of the responses were excluded because of illegible handwriting. We corrected spelling mistakes when they were not ambiguous (e.g., papirus instead of papyrus). The proportions for the whole category set were calculated and are available for consultation/downloading as supplemental materials from http://brm.psychonomic-journals .org/content/supplemental. Usually, responses below the threshold of 5\% are considered as marginal and do not appear in tables. However, for a larger view of the categorization process, responses below this threshold are also shown. Each semantic category is displayed in a separate sheet on the electronic archive. The construction of each table is provided via the example of the category UNE PIERRE PRECIEUSE/A PRECIOUS STONE. Table 2 provides the results for names, totals, and first occurrences for this category.

Names (French/English). This column lists all the exemplars given in response to the category in question. The singular form presentation was adopted in order to maintain consistency. However, a few items remained in the plural form, since their use was only plural (e.g., fondations (foundation). When a French response had two or more translation equivalents, we numbered these responses and gave the different translations (e.g., Boisson 1 and Boisson 2 for beverage and drink, respectively). When a word had various correct spellings, all spellings 


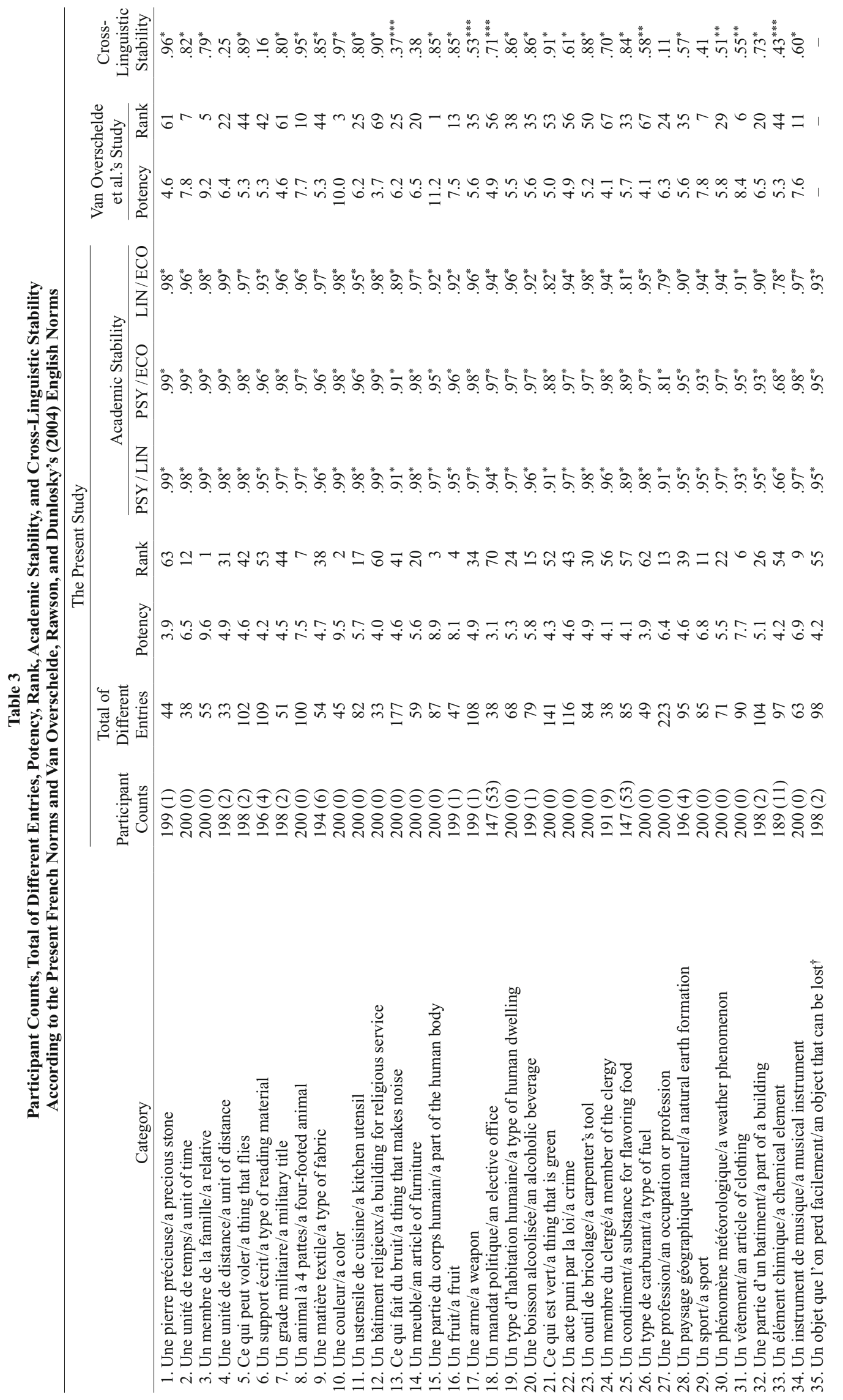




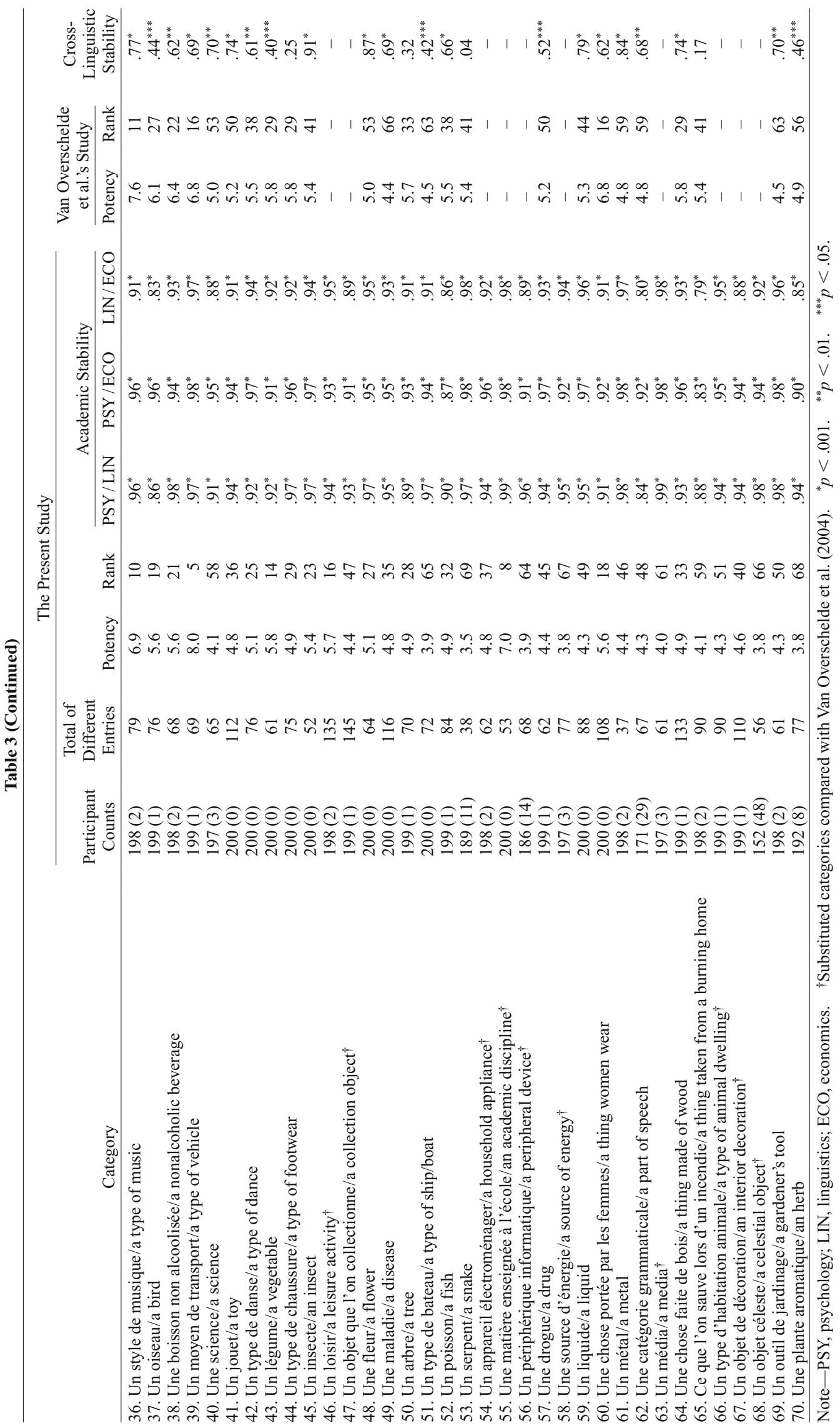


were indicated as a single entry (e.g., hachisch, haschich, hachich). The same procedure was applied when two entries referred to the same meaning (e.g., titane and titanium) ${ }^{2}$

Total. The heading of this column first indicates (in parentheses) the number of participants who gave at least one response for the category in question. Then the column details the proportion for each French exemplar, with the English equivalent when available. The proportion was calculated for each response by dividing the number of participants who gave the considered exemplar by the total number of participants who gave at least one exemplar for the category considered. For instance, in French, for the category UNE PIERRE PRÉCIEUSE/A PRECIOUS STONE, diamant/diamond had a proportion of .89 (178 participants out of a total of 199 gave this response).

First occurrence. Herein, we provide the proportion of participants who gave the response as a first choice. It was calculated by dividing the number of participants who gave the response as a first choice by the total number of participants who gave at least one response in the category. For example, diamant/diamond was given as a first choice with a proportion of .36 (72 participants out of a total of 199 gave this response as a first choice). An empty cell on the First Occurrence column indicates that the exemplar was never given as a first choice. A "-" sign indicates that the exemplar was not present in Van Overschelde et al.'s (2004) study.

In the following, we will present a measure of academic stability, a cross-linguistic comparison, and a languagespecific comparison. Table 3 presents a measure of academic stability according to the three university majors of the participants in our study. It also shows a direct comparison between our French data and Van Overschelde et al.'s (2004) English data. Lastly, Tables 4 and 5 display comparisons between the present study and Marchal and Nicolas's (2003) and Léger et al.'s (2008) studies, respectively. As such, three dependent variables concerning the data set of the whole category were analyzed and are detailed through the headings below (potency, rank, and academic stability; see Table 3).

Participant counts. This column indicates the total number of participants who gave at least one response in the category. The total number of participants who gave no response is provided in parentheses.

Total of different entries. The total number of different entries per category is given (e.g., 44 different entries were given for the UNE PIERRE PRECIEUSE/A PRECIOUS STONE category).

Potency. A measure of category potency was calculated by dividing the total number of responses in the category by the total number of participants who gave at least one response. The average number of responses per category is thus known. For instance, the category UNE PIERRE PRECIEUSE/A PRECIOUS STONE had a potency of 3.9 - that is, 3.9 words were given on average by participants.

Rank of the category. Herein, we indicate the rank obtained by each category as a function of the formerly calculated potency strength. For instance, the category $U N$ MEMBRE DE LA FAMILLE/A RELATIVE has the largest potency strength (this category generated an average of 9.6 words per participant) and, therefore, has a rank of 1 , whereas UN MANDAT POLITIQUE/AN ELECTIVE OFFICE has the smallest strength and therefore a rank of 70 (on average, 3.1 words per participant).

Academic stability. We computed three Pearson product-moment correlation coefficients, one for each pair of majors (psychology, linguistics, and economics), for frequencies with which each response was generated. As was expected, strong positive correlation coefficients were observed, suggesting the generalization of the norms across university majors $(p<.001$ for the whole $r$; see Table 3). This generalization cannot really be compared with the Van Overschelde et al. (2004) and Battig and Montague (1969) generalization, which concerned a geographic stability - that is, students from different regions of the United States. Whereas Balota, Ferraro, and Connor (1991) reported an influence of demographic variability in the collection of imageability norms, our results show an academic stability in categorization norms.

\section{Cross-Linguistic Comparisons (see Table 3)}

Considering potency, the averages for the 59 common categories were $5.29(S D=1.45)$ and $5.91(S D=1.42)$ for the present study and for Van Overschelde et al.'s (2004) study, respectively. The difference was significant $[t(116)=2.34, p<.05]$. Slightly more exemplars were given per category in Van Overschelde et al.'s study. We also performed a Pearson product-moment correlation test on this potency strength between our French and Van Overschelde et al.'s English norms, for available categories. The results showed a strong positive correlation $(r=$ $.90, p<.001)$.

Considering rank, another correlation test was performed on the differences of ranks (Spearman rho) for available categories and again showed a high degree of correlation $(r=.76, p<.001)$. Both of these strong positive correlations indicate that French and English participants have a close quantitative behavior when categorizing.

In order to have a statistical measure of the qualitative similarity of the French and American categorization process, we performed Pearson product-moment correlations between the two sets of frequencies. Since responses below a threshold of 5\% are usually considered as marginal measures, we performed this correlation test only when this threshold was surpassed in one or both languages for each exemplar (see the "Cross-Linguistic Stability" subheading, Table 3). We report, for each of the 59 common categories, the Pearson product-moment correlation coefficient. The observed correlation coefficients ranged from +.04 to +.97 . Although 50 categories showed high correlation coefficients, 9 categories did not reach significance: A UNIT OF DISTANCE, A TYPE OF READING MATERIAL, AN ARTICLE OF FURNITURE, AN OCCUPATION OR PROFESSION, A SPORT, A TYPE OF FOOTWEAR, A TYPE OF SHIP/BOAT, A SNAKE, and A THING TAKEN FROM A BURNING HOME.

\section{Comparison With Other French Norms}

In order to have a measure of the stability between our norms and other recent French norms, we also calculated 
Table 4

Potency and Language-Specific Stability for the Fifteen Shared Categories Between the Present French Norms and Marchal and Nicolas's (2003) French Norms

\begin{tabular}{lccc}
\hline & \multicolumn{2}{c}{ Potency } & $\begin{array}{c}\text { Language- } \\
\text { Category }\end{array}$ \\
\cline { 2 - 4 } & $\begin{array}{c}\text { The Present } \\
\text { Study }\end{array}$ & $\begin{array}{c}\text { Marchal and } \\
\text { Nicolas's Study }\end{array}$ & $\begin{array}{c}\text { Specific } \\
\text { Stability }\end{array}$ \\
\hline Un ustensile de cuisine/a kitchen utensil & 5.7 & 4 & .91 \\
Un meuble/an article of furniture & 5.6 & 4 & .91 \\
Une partie du corps humain/a part of the human body & 8.9 & 4 & .94 \\
Un fruit/a fruit & 8.1 & 4 & .95 \\
Une arme/a weapon & 4.9 & 4 & .93 \\
Un outil de bricolage/a carpenter's tool & 4.9 & 4 & .87 \\
Un vêtement/an article of clothing & 7.7 & 4 & .86 \\
Un instrument de musique/a musical instrument & 6.9 & 4 & .94 \\
Un oiseau/a bird & 5.6 & 4 & .92 \\
Un légume/a vegetable & 5.8 & 4 & .71 \\
Un insecte/an insect & 5.4 & 4 & .92 \\
Une fleur/a flower & 5.1 & 4 & .92 \\
Un arbre/a tree & 4.9 & 4 & .92 \\
Un type de bateau/a type of ship/boat & 3.9 & 4 & .92 \\
Un poisson/a fish & 4.9 & & .61 \\
\hline
\end{tabular}

and compared (when possible) potencies and ranks between our data and those common to Marchal and Nicolas's (2003) and Léger et al.'s (2008) studies. The results are presented in Tables 4 and 5 .

Marchal and Nicolas (2003) versus the present study (see Table 4). Marchal and Nicolas's methodology led to an unchanging potency of 4 . The averages for potency between this study and ours for the 15 shared categories were 4 and 5.89 , respectively $(S D=1.39)$. On average, the participants naturally gave 1.89 additional words per category with the 30 -sec time window methodology used in the present study, as compared with Marchal and Nicolas's methodology, where participants had to give only the first four exemplars that came to mind. Because of the unchanging potency in Marchal and Nicolas's study, neither correlation nor rank computation could be performed.

Léger et al. (2008) versus the present study (see Table 5). The averages for potency between Léger et al.'s study and ours for the 14 common categories were 13.76 $(S D=5.06)$ and $5.92(S D=1.09)$, respectively. With a no-time-constraint methodology, participants gave, on average, 7.84 additional words, as compared with our 30-sec time window methodology. We also performed a Pearson product-moment correlation test on the potency strength between this study and ours. The result shows a positive correlation $(r=.77, p<.01)$. Lastly, a correlation test was performed on the differences of ranks (Spearman rho). The ranks from our study were (re)calculated taking into account the number of common categories. This correlation test showed a high degree of correlation $(r=$ $.85, p<.001)$.

The potency differences arise mainly from three different methods in data collection. As a reminder, in the present study, the participants had to give a maximum number of exemplars in a 30-sec time window; in Marchal and Nicolas's (2003) study, participants had to give only four exemplars; and in Léger et al.'s (2008) study, participants had no time constraints and were encouraged to write a maximum number of exemplars.

As for cross-linguistic comparisons, we computed Pearson product-moment correlation coefficients with the two

Table 5

Potency, Rank, and Language-Specific Stability for the Fourteen Shared Categories Between the Present French Norms and Léger, Boumlak, and Tijus's (2008) French Norms

\begin{tabular}{|c|c|c|c|c|c|}
\hline \multirow[b]{2}{*}{ Category } & \multicolumn{2}{|c|}{$\begin{array}{c}\text { The Present } \\
\text { Study }\end{array}$} & \multicolumn{2}{|c|}{$\begin{array}{c}\text { Léger et al.'s } \\
\text { Study }\end{array}$} & \multirow{2}{*}{$\begin{array}{c}\text { Language- } \\
\text { Specific } \\
\text { Stability }\end{array}$} \\
\hline & Potency & Rank & Potency & Rank & \\
\hline Un meuble/an article of furniture & 5.6 & 8 & 10.4 & 10 & .96 \\
\hline Un fruit/a fruit & 8.1 & 1 & 18.3 & 4 & .93 \\
\hline Une arme/a weapon & 4.9 & 11 & 8.9 & 14 & .92 \\
\hline Une profession/an occupation or profession & 6.4 & 5 & 25.4 & 1 & .83 \\
\hline Un sport/a sport & 6.8 & 4 & 20.2 & 2 & .91 \\
\hline Un vêtement/an article of clothing & 7.7 & 2 & 19.3 & 3 & .91 \\
\hline Un instrument de musique/a musical instrument & 6.9 & 3 & 14.7 & 5 & .91 \\
\hline Un oiseau/a bird & 5.6 & 7 & 11.9 & 7 & .93 \\
\hline Un jouet/a toy & 4.8 & 14 & 9.5 & 13 & .90 \\
\hline Un légume/a vegetable & 5.8 & 6 & 12.8 & 6 & .90 \\
\hline Un insecte/an insect & 5.4 & 9 & 10.4 & 11 & .94 \\
\hline Une fleur/a flower & 5.1 & 10 & 10.5 & 8 & .93 \\
\hline Un arbre/a tree & 4.9 & 13 & 9.5 & 12 & .92 \\
\hline Un poisson/a fish & 4.9 & 12 & 10.5 & 9 & .92 \\
\hline
\end{tabular}


other French norms on the set of exemplars for each category (see Tables 4 and 5, "Language-Specific Stability," and the supplemental materials). Although the methodology used to collect data was different for the three studies, the results showed a large stability in the exemplars produced by our participants and those in the two other recently published French norm studies (all $r$ s, ranging from .61 to .96 , were significant at a $p<.001$ threshold).

\section{DISCUSSION}

To sum up, the norms presented herein, dealing with a large set of categories, provide contemporary information about the dominant exemplars given to a broad range of French categories. Considering the large number of participants coming from different majors and the large set of categories tested, these norms provide a strong test of this process in French and could be useful in building experimental materials that necessitate control of semantic aspects. The strong academic stability across our three majors suggests generalization across university majors.

For the purpose of providing a French-English comparison in a common time period, we adopted Van Overschelde et al.'s (2004) methodology. A cross-linguistic comparison with both quantitative and qualitative analyses is available. First, a quantitative test showed a significant difference between the French categorization in the present study and the English categorization in Van Overschelde et al.'s study for the measure of the potency average (a slightly greater number of exemplars - on average, 0.6 word - was given in Van Overschelde et al.'s [2004] study). On the other hand, a strong stability was attested to by correlations of both potency and rank. Second, the qualitative test performed on each category between the two studies mainly showed stability ( 50 out of 59 shared categories had a significant correlation coefficient), indicating a large semantic knowledge overlap in French and English.

Surprisingly, some quite usual categories seem to be language specific (UNE PROFESSION/AN OCCUPATION and UN SERPENT/A SNAKE, for instance; see the complete list of language-specific categories in the Results section), whereas, as could be expected, other categories showed a large overlap in the exemplars given and their respective frequencies (e.g., UN ANIMAL $\dot{A}$ QUATRE PATTES/A FOURFOOTED ANIMAL and UNE COULEUR/A COLOR). Nevertheless, a strong correlation between the responses in the two languages for a category should be considered with caution, especially when the frequency of the most typical exemplars differs. For instance, although the correlation for the global category UN LÉGUME/A VEGETABLE was significant, the French exemplar courgette was almost 10 times more frequent than its American English translation zucchini. Thus, the building of semantic experimental materials must be based on word-by-word checking and not on the basis of the category as a whole.

In the past, the relative lack of non-English categorization norms has led researchers focused on memory structure to derive their material from English norms without taking account of linguistic/cultural biases. The necessity of using language-specific categorization norms to control for so- ciocultural influences has also been underlined by Cordier (2002), Malt, Sloman, and Gennari (2003), and Yoon et al. (2004) in an intercultural and interage comparison for the latter. Moreover, the translation of an item should not be considered as a perfect equivalent between two languages. All these considerations must be taken into account when experiments dealing with semantic aspects are run.

The necessity of using well-built and languageappropriated categorization norms can also be justified by a recent challenge in traditional behavioral tasks. For decades, a massive recourse to the lexical decision task (mostly based on associative norms) prevailed over other behavioral tasks, although the lexical decision task may not be best suited when early processes of semantic memory are studied. Semantic recovery can be facilitated in categorization tasks, as compared with lexical decision tasks, as has been shown by McRae and Boisvert (1998) with a 250-msec SOA and by Grainger and Frenck-Mestre (1998) and Bueno and Frenck-Mestre $(2002,2008)$ with short SOAs (43 and $57 \mathrm{msec}$ ). As such, it may be preferable for online categorization tasks to be based on semantic categorization norms rather than associative ones.

Given the interest of the cross-linguistic approach in distinguishing what is relevant to universal processes from what is language specific, and given the burst of studies aimed at comparing monolinguals with bilinguals, the present norms should be useful for future research. Indeed, for further studies whose focus is on cross-linguistic differences and on bilingual semantic structure, the present comparison is a precious tool for controlling linguistic materials. However, it is limited to studies conducted in the French and English languages. Further studies are necessary to broaden these comparisons to other languages (e.g., Spanish, Portuguese, and Chinese).

Stability across the present norms and other recently published French norms (Léger et al., 2008; Marchal \& Nicolas, 2003) is attested to by several comparisons presented herein. First, a quantitative stability is shown through the Spearman rho test between the ranks of the shared categories (test available only for the comparison with Léger et al., 2008). Despite methodological differences across studies, a strong qualitative stability is also reported. Correlation coefficients (computed on the 15 and 14 shared categories) between data from the present study and those from the two other French norms are both high and reliable. As such, the present study cannot be considered to be a global update of these recent published norms but, rather, as a test of their stability and, above all, as a complement (55 and 56 additional categories, respectively).

Although existing in English, norms for a large set of categories have been lacking in French. The present study fills in this gap and provides the largest French categorization norms to date.

\section{AUTHOR NOTE}

We are grateful to Cheryl Frenck-Mestre, from the Université de Provence-CNRS, for invaluable feedback on earlier drafts. We are also grateful to the three anonymous reviewers for their comments and recommendations. Correspondence concerning this article should be addressed to S. Bueno, Université de Paris 13, UFR LSHS/UTRPP, EA 
3413, 99 avenue Jean-Baptiste Clément, 93430 Villetaneuse, France (e-mail: bueno@univ-paris13.fr).

\section{REFERENCES}

Balota, D. A., Ferraro, F. R., \& Connor, L. T. (1991). On the early influence of meaning in word recognition: A review of the literature. In P. J. Schwanenflugel (Ed.), The psychology of word meaning (pp. 187-218). Hillsdale, NJ: Erlbaum.

Battig, W. F., \& Montague, W. E. (1969). Category norms for verbal items in 56 categories: A replication and extension of the Connecticut norms. Journal of Experimental Psychology: Monograph, 80, 1-46.

Bueno, S., \& Frenck-Mestre, C. (2002). Rapid activation of the lexicon: A further investigation with behavioral and computational results. Brain \& Language, 81, 120-130.

Bueno, S., \& Frenck-Mestre, C. (2008). The activation of semantic memory: Effects of prime exposure, prime-target relationship, and task demands. Memory \& Cognition, 36, 882-898.

Charles, A., \& TARDIEU, H. (1977). Tables de fréquence des éléments de 28 catégories [Frequencies database for exemplars of 28 categories]. Paris: Université René Descartes, Laboratoire de Psychologie Expérimentale.

Cohen, B. H., Bousfield, W. A., \& Whitmarsh, G. A. (1957). Cultural norms for verbal items in 43 categories (Tech. Rep. 22). Storrs: University of Connecticut.

Cordier, F. (1980). Gradients de prototypie pour 5 catégories sémantiques [Degrees of prototype for 5 semantic categories]. Psychologie Française, 25, 211-219.

Cordier, F. (2002). Les théories conceptuelles [Theories of concepts]. In F. Cordier \& J. François (Eds.), Langage et catégorisation (pp. 125144). Paris: Hermès.

Cree, G. S., \& MCRAe, K. (2003). Analyzing the factors underlying the structure and computation of the meaning of chipmunk, cherry, chisel, cheese, and cello (and many other such concrete nouns). Journal of Experimental Psychology: General, 132, 163-201.

Dehaene, S., Naccache, L., Le Clec'H, G., Koechlin, E., MuelLer, M., Dehaene-Lambertz, G., ET AL. (1998). Imaging unconscious semantic priming. Nature, 395, 597-600.

Denis, M. (1978). Normes catégorielles pour un échantillon de 16 termes généraux [Norms for a sample of 16 categories]. Paris: Université de Paris 8 .

Dubois, D. (1983). Analyse de 22 catégories sémantiques du français: Organisation catégorielle, lexique et représentation [An analysis of 22 French semantic categories: Categorical organization, lexicon and representation]. L'Année psychologique, 83, 465-489.

Ferrand, L., \& Alario, F. X. (1998). Normes d'associations verbales pour 366 noms d'objets concrets [Word association norms for 366 names of objects]. L'Année Psychologique, 98, 657-709.

Grainger, J., \& FrencK-Mestre, C. (1998). Masked priming by translation equivalents in bilinguals. Language \& Cognitive Processes, 13, 601-623.

Imbs, P., Martin, R., \& Centre de Recherche Pour Un Trésor de la Langue FrançaISE (1971). Dictionnaire des fréquences [Dictionary of frequencies]. Paris: Didier.

Léger, L., BoumlaK, H., \& TiJus, C. (2008). BASETY: Extension et typicalité des exemplaires pour 21 catégories d'objets [BASETY: Extension and typicality of the specimens for 21 categories of objects]. Canadian Journal of Experimental Psychology, 62, 223-232.

Luo, L., \& Craik, F. I. M. (2008). Aging and memory: A cognitive approach. Canadian Journal of Psychiatry, 53, 346-353.
Malt, B. C., Sloman, S. A., \& Gennari, S. (2003). Universality and language specificity in object naming. Journal of Memory \& Language, $49,20-42$.

Marchal, A., \& Nicolas, S. (2003). Normes de production catégorielle pour 38 catégories sémantiques: Etude sur des sujets jeunes et âgés [Category generation norms for 38 semantic categories in young and older subjects]. L'Année Psychologique, 103, 313-366.

Masson, M. E. J. (1995). A distributed memory model of semantic priming. Journal of Experimental Psychology: Learning, Memory, \& Cognition, 21, 3-23.

McRae, K., \& Boisvert, S. (1998). Automatic semantic similarity priming. Journal of Experimental Psychology: Learning, Memory, \& Cognition, 24, 558-572.

McRae, K., Cree, G. S., Seidenberg, M. S., \& McNorgan, C. (2005). Semantic feature production norms for a large set of living and nonliving things. Behavior Research Methods, 37, 547-559.

NeELY, J. H. (1991). Semantic priming effects in visual word recognition: A selective review of current findings and theories. In D. Besner \& G. W. Humphreys (Eds.), Basic processes in reading: Visual word recognition (pp. 264-336). Hillsdale, NJ: Erlbaum.

Plaut, D. C. (1995). Semantic and associative priming in a distributed attractor network. Proceedings of the Seventeenth Annual Conference of the Cognitive Science Society, 17, 37-42.

Plaut, D. C., \& Bоoth, J. R. (2000). Individual and developmental differences in semantic priming: Empirical and computational support for a single-mechanism account of lexical processing. Psychological Review, 107, 786-823.

Quinn, W. M., \& Kinoshita, S. (2008). Congruence effect in semantic categorization with masked primes with narrow and broad categories. Journal of Memory \& Language, 58, 286-306.

Tourrette, G. (1979). Table catégorielles: Normes de production dans 30 catégories sémantiques [Categorical tables: Generation norms for 30 semantic categories]. Poitiers: Université de Poitiers, Laboratoire de Psychologie.

Van Overschelde, J. P., Rawson, K. A., \& Dunlosky, J. (2004). Category norms: An updated and expanded version of the Battig and Montague (1969) norms. Journal of Memory \& Language, 50, 289-335.

Yoon, C., Feinberg, F., Hu, P., Gutchess, A. H., Hedden, T., Chen, H.-Y. M., ET AL. (2004). Category norms as a function of culture and age: Comparisons of item responses to 105 categories by American and Chinese adults. Psychology \& Aging, 19, 379-393.

\section{NOTES}

1. Although Van Overschelde et al. (2004) recorded time responses, this measure did not appear relevant to us, for two reasons. First, in their study, the delay was recorded from the onset of the category name to the moment the participant pressed the "Enter" key (when done typing the word). A large variance in typing ability was undoubtedly present. Second, word length was confounded with time necessary for typing (short words are undoubtedly quicker to type than long words).

2. The electronic version of the Trésor de la langue française (Imbs, Martin, \& Centre de Recherche pour un Trésor de la Langue Française, 1971) was used to check spelling and definition of words (URL: http:// atilf.atilf.fr/tlf.htm)

\section{SUPPLEMENTAL MATERIALS}

The French category norms discussed in this article may be downloaded from http://brm.psychonomic-journals.org/content/supplemental. 


\section{APPENDIX}

\section{INSTRUCTIONS}

AGE:

GENDER:

MAJOR:

L1 (MOTHER TONGUE):

You will find the name of a category on each odd page of this booklet

For example: "A STATIONERY"

Your task will be to give a maximum of exemplars belonging to this category.

For instance, for the category "A STATIONERY," you could give as answers:

- Paperclip

- Pen

- Stapler

- Ruler

- Binder

- Paper

- Glue

- ...

The experimenter will give you the start signal.

Every 30 seconds, the experimenter will inform you, with a "beep," to turn the page and change the category you are working on. You only have $\mathbf{3 0}$ seconds per category to perform the task (i.e., give a maximum of exemplars within this time window). You can neither continue working on a category once a new beep is given nor go back to complete a previous category. Two breaks will be proposed during the session of data collecting.

Please use a legible handwriting as much as you can (thereafter, your answers will be manually entered in an electronic spreadsheet by experimenters).

Do you have any questions?

(Manuscript received January 7, 2009;

revision accepted for publication June 26, 2009.) 